\title{
DE LA POLÉMICA AL EQUILIBRIO. NOTAS SOBRE LA DICCIÓN DEL VERSO Y LA ADAPTACIÓN DEL TEXTO EN LA PUESTA EN ESCENAACTUAL DEL TEATRO CLÁSICO ESPAÑOL ${ }^{1}$
}

\author{
Purificació Mascarell \\ Universidad Complutense de Madrid-Universitat de València \\ purixinela@hotmail.com
}

\begin{abstract}
RESUMEN: Estas notas plantean un balance y un estado de la cuestión en torno a las dos problemáticas que más han marcado la recepción crítica de la puesta en escena de los dramaturgos clásicos españoles a lo largo del siglo XX: la dicción del verso y la adaptación de los textos áureos.

PALABRAS CLAVE: Siglo de Oro, puesta en escena, dicción, verso, adaptación, texto.
\end{abstract}

\section{CONTROVERSE ET ÉQUILIBRE. NOTES SUR LA DICTION DU VERS ET L'ADAPTATION DU TEXT DANS LA MISE EN SCÈNE ACTUELLE DU THÉÂTRE CLASSIQUE ESPAGNOL}

\footnotetext{
RÉSUMÉ: Ces notes présentent un bilan et un état de la question autour des deux problèmes qui ont marqué la réception critique de la mise en scène des dramaturges classiques espagnols au long du XXe siècle: la diction de vers et l'adaptation des textes baroques.

MOTS CLÉS: Âge d'Or, mise en scène, diction, vers, adaptation, texte.
}

Recibido: 17/12/2015. Aceptado: 27/07/2016

Recientemente he tratado de demostrar cómo el público actual, ajeno a los principales escollos ideológicos que han lastrado la recepción del teatro clásico español entre las generaciones anteriores, es ahora capaz de recrearse en el entretenimiento, la belleza, las emociones y la reflexión que la obra barroca le

1. Mi trabajo se beneficia de mi vinculación a los proyectos de investigación financiados por el MICINN con los números de referencia FFI2008-00813, CDS2009-00033, FFI2011-23549 y FFI201566393-P. 
proporciona desde las tablas. Ello ha sido posible gracias a montajes innovadores y rupturistas defendidos por las múltiples compañías privadas que, desde principios de los $80 \mathrm{y}$, especialmente, desde el cambio de milenio, han revisitado las obras clásicas, así como gracias a la labor desarrollada por la principal compañía pública encargada de representar a Lope y el resto de dramaturgos áureos, la $\mathrm{CNTC}^{2}$. Al mismo tiempo que los espectadores se han ido alejando de los prejuicios vinculados a la etapa franquista ${ }^{3}$, desde el ámbito académico se ha comenzado a valorar los espectáculos de teatro clásico más allá de dos parámetros básicos que han condicionado su recepción especializada a lo largo del siglo XX: el modo de decir el verso y el tipo de adaptación textual realizada sobre el original. Precisamente, este artículo trata de esbozar un balance general de la evolución de estas dos problemáticas y su estado actual.

Sostiene Huerta Calvo que "la de decir el verso es una cuestión que la crítica aduce siempre que puede como mal endémico de la puesta en escena de los clásicos, aunque ya no se sabe si lo endémico es un mal de la misma crítica que plantea el problema” (2006: 65). En efecto, el tema fue adquiriendo tintes obsesivos a medida que avanzaba el siglo $\mathrm{XX}$ : si durante las primeras décadas la manera de entonar los versos es comentada de modo descriptivo en las críticas de los espectáculos, desde los años 60 comienza a convertirse en el caballo de batalla de una crítica que rara vez expone las características de una buena dicción, pero no se cansa de añadir a sus artículos la casi muletilla de "los actores no decían bien el verso". Esta evolución es perceptible a través de los dos volúmenes editados por el Centro de Documentación Teatral bajo el título Historia de los Teatros Nacionales (1993 y 1995). Sus páginas recogen fragmentos de críticas de la época sobre los espectáculos de Lope o Calderón, unas citas que evidencian cómo, a lo largo del siglo XX, la forma de interpretar el verso ha constituido una preocupación que ha ido radica-

2. Mi tesis doctoral, El Siglo de Oro español en la escena pública contemporánea. La Compañía Nacional de Teatro Clásico (1986-2011), Universitat de València, 2014, trata precisamente de analizar la misión artística desempeñada por la Compañía Nacional de Teatro Clásico desde los escenarios para erradicar el concepto de teatro clásico como sinónimo de aburrimiento y conservadurismo. En la tesis se analizan los diez montajes más significativos de la CNTC desde su fundación en 1986 hasta el año 2011 y se constata en ellos una voluntad de renovación de los lenguajes escénicos a la hora de abordar el clásico. Esta apuesta estética, entre otras causas, ha hecho posible un cambio de paradigma en el imaginario social sobre los clásicos españoles: Lope, Calderón y el resto de autores barrocos empiezan a considerarse como nuestros contemporáneos, a la manera en que Shakespeare lo es desde hace décadas para su público anglosajón.

3. Para un panorama de la escena clásica durante el franquismo y sus usos políticos, véase la tesis doctoral de Manuel Muñoz Carabantes Puesta en escena y recepción del teatro clásico y medieval en España (desde 1939 a nuestros dias), Universidad Complutense de Madrid, 1992. 
lizándose hasta convertirse en un tópico de la crítica. Y, sin duda, los años ochenta constituyeron la década más problemática con respecto a esta cuestión.

Ciertamente, en el pasado siglo, todo intento de naturalizar el verso fue condenado o alabado en función del sector de la crítica que juzgara ${ }^{4}$. La opinión se dividía en dos bandos que, por otro lado, representan las dos variantes de espectadores de drama áureo fundamentales durante el siglo XX: los que disfrutan de la declamación ampulosa que enfatiza la rima y los componentes versales, y los que desean gozar del teatro barroco en un marco interpretativo cercano al naturalismo. La escuela romántica siempre ha tenido seguidores que no han visto como un defecto interpretativo la expresión ahuecada, la entonación monótona, el tono elevado o el latiguillo, ese alargamiento reiterativo del final de cada metro que, según el gusto y la costumbre del espectador, resulta una suplicio o música celestial. Pero, ¿cuál es la opción interpretativa idónea?:

Siempre estamos oyendo: "Los actores no saben decir el verso”. Pero, ¿cómo se debe decir el verso? [...]. Posiblemente nunca ha habido una manera. Hubo actores que crearon una manera de decir el verso que se fue pasando de unos a otros. Pero yo dudo mucho que haya habido una determinada manera de decir el verso. José Luis Alonso siempre afirmaba: "El verso no se dice de una manera o de otra, se dice sencillamente bien, que se entienda”. No sé ese “bien” cómo es. (Peláez 1996: 323)

Aunque algunos especialistas como Peláez han expresado sin ambages su desconocimiento del supuesto modelo del bien decir, el debate ha sido frecuente no solo entre la crítica periodística, sino también en las mesas redondas y los debates programados dentro de las jornadas o congresos de especialistas celebrados en las últimas décadas. En estos encuentros ha sido frecuente escuchar el lamento de participantes y asistentes ante la forma de declamar el verso por parte de los actores contemporáneos. Y ello sin atreverse nunca a hacer una demostración de la opción acertada de trabajo. En este sentido, y dentro de su línea tan irónica como antiacadémica, Marsillach apuntaba:

La cultura tiene una tendencia a lo oscuro, a lo secreto, a lo elitista. Yo creo que a ciertas personas les conviene decir que esto del verso es una cosa muy difícil, casi imposible, y que los clásicos son muy complicados y delicados. Son gentes que cotizan muy bien sus conferencias sobre el tema. Pero detrás de eso pienso que es más sencillo de lo que se supone. Hay un problema de sentido común y de oído.

4. Para un panorama general de las tradiciones actorales modernas frente al verso clásico, véase Evangelina Rodríguez Cuadros (2012: 195-247). También Juan José Granda Martín (2000: 13-27). 
Lo cierto es que aprenderse bien un libro de métrica no resuelve el problema de los actores, porque no solo deben recitar, sino, sobre todo, representar un personaje. (Medina Vicario 1987: 34)

Los años de sordo enfrentamiento entre teóricos y profesionales de la escena en torno a la dicción ideal del verso han dejado paso a posturas aperturistas que entienden el verso como el instrumento expresivo a través del cual se traslada la acción y el pensamiento al espectador. Este trasvase, por tanto, debe hacerse de un modo inteligible más allá de la condición poética o musical de la composición en verso. Siguiendo esta perspectiva, desde el ámbito académico han surgido voces que tildan de erróneo el tipo de análisis de la dicción del verso que ha caracterizado a la academia hasta hace bien poco. Pérez-Rasilla, representante de esta nueva forma de abordar "la cuestión del verso", se pregunta atinadamente:

¿Habrá de quedarse la crítica en el plano normativo -o pretendidamente normativo- y evaluar si "se dice bien" o no el verso, conforme a hipotéticas tradiciones o a criterios procedentes de tratados o manuales o habrá que preguntarse además por la función dramática y estética que para el espectador actual puede desempeñar una herramienta expresiva tan rígida $\mathrm{y}$, a la vez, tan eficaz dramáticamente? (2008: 11-12)

Pero, en gran medida, si la crítica ha dejado de obsesionarse con la cuestión de cómo se dice bien el verso en un espectáculo de teatro clásico, se debe a la superación de este conflicto en los escenarios. Y ello gracias al hallazgo de una fórmula expresiva contemporánea que agrada a la gran mayoría y ha logrado desactivar un conflicto que, durante décadas, ha figurado en el centro de las desavenencias entre crítica y profesionales del teatro. Esta fórmula está basada en la búsqueda de un equilibrio interpretativo que, sin renegar de la musicalidad y la artificialidad inherentes a las composiciones dramáticas clásicas, transforme la palabra en sentimiento y en acción sobre las tablas.

En 1986, ante el montaje de El castigo sin venganza del director Miguel Narros, el crítico Florencio Segura denunciaba la costumbre de aderezar los textos clásicos en escena para desviar la atención del público fuera del verso. Una crítica que, en los años 80, recibieron algunos montajes de Marsillach al frente de la CNTC, como Antes que todo es mi dama (1987)5. La opinión de Segura,

\footnotetext{
5. Para un análisis detallado de los elementos escénicos puestos en juego por Marsillach para destacar la condición de artefacto teatral de esta comedia, véase Purificació Mascarell (2014).
} 
pese a estar basada en prejuicios contra el naturalismo teatral y en la inclinación personal del crítico por las maneras románticas de interpretar obras clásicas, resulta interesante porque pone en evidencia la inexistencia de un consenso sobre la forma de interpretar y recibir los textos en verso:

En España hace ya años que nuestros directores intentan inútilmente hacer perdonar a los textos clásicos el que estén escritos en verso y aborrecen y escapan de todo lo que pueda oler a convencionalismo o artificio porque están obsesionados con un naturalismo a ultranza y anticuado. El resultado es siempre el mismo: los textos clásicos no se potencian, se disfrazan. Y como no hay más remedio que cargar con el verso, se busca entonces aliviar la situación acumulando en el escenario "otras" bellezas: escenografías suntuosas, figurines originales, música, color, movimiento... Cuando se desconfía del texto o de la capacidad del público para asimilarlo siempre se acude al pretexto que lo aligere o que lo camufle. (1986: 6)

Sin embargo, tan solo veinticinco años después, Huerta Calvo no duda en aseverar que se ha roto el corsé del temor al verso y se ha encontrado una opción de trabajo ajustada a las necesidades teatrales del presente. En este camino hacia la normalización interpretativa del verso, los esfuerzos realizados desde la CNTC han resultado fundamentales:

\begin{abstract}
¿Será verdad que nunca como en estos veinticinco años se han dicho tan bien los versos de la Comedia? A los espectadores más veteranos quizás no se lo parezca. Tienen acostumbrado el oído a la declamación -en general bastante impostada- de un Guillermo Marín o de un Manuel Dicenta, tan enormes actores por otro lado. Frente a esa tradición grandilocuente, sin duda propia de la escuela romántica, Marsillach se propuso desde un primer momento la naturalidad como principio básico, y es esta la escuela que han seguido, mejorándola, si cabe, los directores posteriores, hasta llegar a la difícil sencillez de la etapa de Vasco. (2012: 80)
\end{abstract}

La CNTC -sin que la institución lo haya pretendido de manera programática, más bien a través de tentativas, aproximaciones y apuestas personales de sus directores- ha logrado consolidar una manera de decir el verso que ha concitado la aprobación de especialistas y público en general. Así lo reconoce Roberto Alonso, quien fue director adjunto de la Compañía durante la etapa de Marsillach:

Cuando llegó la CNTC una de las cosas que muchos se plantearon fue que la Compañía les iba a enseñar a decir el verso: "por fin la CNTC nos va a hacer la panacea para que todo este problema y discusión de años de cómo decirse el verso 
la podamos solucionar”. Y no; la Compañía intentó decir el verso de una manera inteligible, clara, evidentemente respetando una serie de cuestiones que deben respetarse, pero no dio una receta de nada a nadie. (2001: 267)

Sin dar recetas, la CNTC ha contribuido a disolver el conflicto del verso gracias a un acercamiento desprejuiciado al mismo. En la actualidad, los directores de escena españoles cuentan con un escuadrón actoral sobradamente familiarizado con el verso clásico: Joaquín Notario, Arturo Querejeta, Pepa Pedroche, Carlos Hipólito, José Luis Santos, Daniel Albaladejo, Nuria Gallardo, Fernando Cayo, o entre los jóvenes, Eva Rufo o David Boceta... Mientras unos se convierten en referencia para las nuevas generaciones, estas aprenden los entresijos técnicos de la métrica y la rima en las escuelas de arte dramático.

Y aunque todavía falta la implantación definitiva de asignaturas específicas de verso clásico en muchas escuelas del territorio español, ya nadie discute que el buen trabajo con el verso también requiere de formación. De hecho, la RESAD ha sido pionera en incluirlo con el máximo rigor dentro de sus planes de estudio y el resultado es que la gran mayoría de actores seleccionados por Joven Compañía Nacional de Teatro Clásico en sus tres promociones provienen de estas aulas madrileñas.

Actualmente, además, la CNTC apuesta por experimentos tales como su reciente colaboración con el Complejo Teatral de Buenos Aires, en el marco de Laboratorio América. Un proyecto centrado en la transformación del verso español en Latinoamérica a través del tiempo y en la apertura de nuevos caminos de investigación para la puesta en escena del patrimonio teatral barroco mediante el maridaje de culturas de habla hispana. El director Guillermo Heras se ha encargado de la coordinación del taller de quinientos jóvenes actores y del montaje resultante: Los áspides de Cleopatra, estrenado en abril de 2013 con un elenco de ocho actores argentinos que han aportado su acento y entonación porteña al verso de Francisco Rojas Zorrilla.

Este ejemplo de apertura demuestra que cada época, cada periodo histórico, tiene su forma de abordar el verso, puesto que la tradición de interpretarlo en escena se crea y se destruye con el paso del tiempo. La dicción del verso, como cualquier aspecto teatral, está sujeta a las modas y tendencias escénicas. Para los amantes de los viajes al pasado, sería interesante -si no resultase imposible por la escasez documental- recuperar la dicción del verso de la época barroca. Constituiría un experimento historicista que proporcionaría nuevos datos para entender la representación barroca, pero que no crearía nuevos espectadores de 
teatro clásico en este siglo. Porque la supervivencia del teatro barroco depende, en gran medida, de su adaptación a los estilos interpretativos del momento. No en vano los directores pugnan por hallar un modelo que conecte emocionalmente con el público y le acerque el mensaje del autor de la forma más nítida posible. Pilar Miró lo consiguió en su exitosa adaptación cinematográfica de El perro del hortelano, donde las palabras áureas cautivaron al espectador gracias a dos interpretaciones paradigmáticas, la de Emma Suárez como la condesa de Belflor y la de Carmelo Gómez como su secretario ${ }^{6}$.

De hecho, el cambio de modelo interpretativo del verso clásico entre los actores contemporáneos ha sido fundamental para la entrada del teatro barroco en la posmodernidad. A fecha de hoy, los actores españoles entienden el verso como un instrumento expresivo de gran belleza poética y musical pero, sobre todo, como un vehículo de comunicación y de expresión de ideas. En este sentido, merece la pena recuperar la opinión del actor Carlos Hipólito, considerado un referente en naturalidad y elocuencia al actuar en verso:

Para mí, y esto es una opción muy personal, el verso ha de sonar natural, fluido, respirado, fácil, por complicada que sea su estructura. Y con esto no quiere decir que el verso, en aras de una mayor comprensión por parte del espectador, deba prosificarse. No. El verso es verso y no prosa, y debe sonar como tal. El actor debe respetar sus reglas, su métrica, su sonoridad. Pero no debemos olvidar que el personaje habla en verso porque piensa en verso. No debemos olvidar que es su forma natural de expresarse. [...] Los actores que, interpretando personajes de una obra de teatro en verso, salen al escenario a recitar, se equivocan. Porque una obra de teatro no es un recital. [...] Y es que ese verso está dentro de una acción. El personaje no sólo habla. Le están pasando cosas mientras lo hace. Y es fundamental compaginar ambas cosas. Por un lado, el verso debe "sonar", pero, por otro, la acción debe atrapar al espectador. Y, llegado el caso de tener que elegir entre dar primacía a una de estas dos líneas maestras [...], siempre será más importante una pausa dramática que una pausa versal. Siempre preferiré romper un verso que permitir que el no romperlo me impida tener el tiempo necesario para una mirada, un gesto, cualquier cosa que, allí, sobre el escenario y en plena acción dramática, me ayude a darle dimensión y verosimilitud a la escena. (1999: 77)

Si la dicción del verso ha sembrado la polémica a lo largo del pasado siglo en debates y críticas, no menos problemática ha resultado la cuestión de cómo

6. Para un análisis del éxito de este film, véase Duncan Wheeler (2012). 
adaptar los textos originales áureos para llevarlos a la escena contemporánea7 . En la década de los 80, con el renacimiento de la puesta en escena de los clásicos, el tema se convirtió en motivo de debate frecuente. Eran unos años en que se luchaba por sentar las bases para la escenificación de los clásicos en democracia, y las Jornadas de teatro clásico de Almagro ofrecían el mejor marco para la reflexión colectiva. Las actas de las jornadas celebradas en 1982 (Hormigón, 1983) recogen opiniones tan dispares como convincentes al respecto: desde posiciones respetuosas con la creación original, como la de Domingo Ynduráin, hasta enfoques de transgresión, como el de Francisco Nieva, los puntos de vista de Guillermo Heras, Ramón Cercós Bolaño, Luis de Taviria, Domingo Miras o José Sanchis Sinisterra todavía siguen siendo útiles para abordar el tema. Entre todos ellos, Nieva lanzó aseveraciones de tono desacralizador y subversivo que hoy, tras más de treinta años de adaptaciones de todo tipo, han perdido parte de su fuerza revulsiva:

Vaya por donde quiera la adaptación o la depredación de los clásicos. Vivan cuanto puedan vivir en los nuevos tiempos. Adáptense, si pueden, o piérdanse antes de resucitar. Pues, en todo caso, este mundo es nuestro y su compromiso lo establece con los vivos y no con los muertos. No soy yo, individualmente, el que ha cortado las amarras de seguridad con el pasado. Soy yo quien, a fin de cuentas, ha quedado solo frente al público que me ha sido dado y, ante cualquier demasía que yo pueda cometer contra los clásicos venerados pido al crítico que tenga la gentileza de ponerse en mi lugar. (1983: 57)

Nieva rogaba empatía profesional, pero lo cierto es que la figura del adaptador, situado a caballo entre dos épocas, correa de transmisión entre un texto antiguo y el espectador actual, ha visto con frecuencia cuestionada su tarea en la

7. No puede olvidarse que la necesidad de los profesionales del teatro de adecuar los textos para subirlos a las tablas existe desde el mismo siglo XVII. Y que durante el XVIII y XIX las refundiciones - "una refundición es una obra basada e inspirada en cierto texto de una época anterior en la cual un autor determinado ha rehecho la obra con tales modificaciones para que resulte ser otra”, (Bingham Kirby 1992: 1005)- funcionaron como el sistema más usual para acoplar los textos de Lope o Calderón al gusto de la época. La cuestión llega a los años 30 del pasado siglo en España, cuando Lorca prefiere adaptar frente a refundir con el objetivo, sobre todo, de acortar la duración de las obras y de avivar el ritmo dramático desde el respeto a la belleza de los versos originales. El concepto de adaptación es, de hecho, propio del siglo XX. Su sentido lo explica bien Sanchis Sinisterra, un dramaturgo con experiencia en la adaptación de los clásicos: "En el teatro el texto es sólo una parte del camino, falta la puesta en escena. Y para ello, generalmente, se requiere un trabajo previo: la versión o adaptación. Las versiones, por definición, nunca son del todo respetuosas con el texto original, ya que están impregnadas de elementos subjetivos de su creador. El mostrar a Calderón visto por” (2006: 177). 
modernidad. El peso de la etiqueta de clásico y el nombre canonizado de Calderón o Lope no ha facilitado que su trabajo se viera con la misma indiferencia que el de cualquier adaptador de textos modernos o contemporáneos. De nuevo, dos bandos distintos de la crítica se identifican con los dos extremos del trabajo adaptador. Por un lado, se encuentran los defensores de la pureza del texto y de su mantenimiento intacto en la actualidad. Por otro, aquellos que defienden la máxima libertad para trabajar los versos del pasado en el presente. En medio, por supuesto, y conformando el grupo más grueso y variado, los que creen que debe llegarse a un punto intermedio, a un equilibrio ideal entre el respeto y la actualización.

Los partidarios del primer bando esgrimen, en su favor, -y además del respeto hacia el autor, a su creación original y a la época que la hizo posible- la fascinación que genera entre el público un lenguaje alejado de lo cotidiano; ese extrañamiento -a la manera entendida por los formalistas rusos- que provoca escuchar vocablos característicos del Setecientos español y hoy tan solo activos en los textos clásicos. En esta línea, defienden el ensanchamiento cultural que supone para cualquier espectador el hecho de entrar en contacto con el castellano de la época de Góngora y Quevedo. Para ello, se parte del presupuesto de considerar al público como un receptor culto e inteligente al que le gustan los retos teatrales.

Por su parte, los defensores de la necesaria actualización del texto arguyen que el alejamiento generado por un lenguaje desconocido provoca rechazo hacia el teatro clásico, el cual se percibe por la gran mayoría como un arte elitista para una minoría preparada y capaz de disfrutarlo. Asimismo, lo juzgan como un ejercicio de pura arqueología que olvida la evolución histórica del castellano y de la sociedad que lo habla. Piensan que si Lope o Calderón estuvieran en el siglo XXI, aceptarían los cambios necesarios en sus obras para llegar al mayor número de ciudadanos.

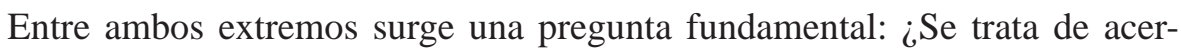
carse al texto del XVII o de aproximar el texto al espectador de hoy? La respuesta es compleja y comprende aspectos culturales, artísticos y educativos. Un especialista como Bernard Dort es consciente del reto "casi contra natura" que supone escenificar una pieza de hace siglos y, por ello, previene sobre la paradoja que habita en todo texto clásico cuando se intenta llevar hoy a las tablas: dramatique a lieu devant nous, spectateurs. Les paroles et les gestes des acteurs- 
personnages s'échangent, s'opposent ou s’allient, dans l'instant. L’imparfait, ce temps des grands récits, y est inconcevable. Mettre dans la bouche de comédiens des textes écrits, leur faire exécuter des mouvements prescrits, il y a parfois plusieurs siècles, a quelque chose de paradoxal. Presque contre nature. (1988: 51)

Para conectar el pasado de la escritura con el presente del equipo artístico y del receptor evitando extrañamientos bruscos, el adaptador dispone de diversos recursos. La opción más socorrida es la reducción o peinado mediante el corte o la eliminación de versos e, incluso, escenas enteras, casi siempre porque resultan accesorias para la trama. Así, en casi todas las adaptaciones es posible detectar supresiones de pasajes o de fragmentos que, en el original y vistos desde una perspectiva contemporánea, resultan reiterativos, prolijos, excesivamente descriptivos o exageradamente retóricos. También es frecuente que se prescinda de alusiones a detalles superfluos o anecdóticos: una referencia geográfica relevante en su momento, la mención de un hecho histórico ya olvidado ${ }^{8}$.

Pero la intervención del adaptador en el texto áureo puede ir más lejos. Un segundo estadio en la adaptación de los textos clásicos lo constituye la sustitución de versos o escenas por otros versos o fragmentos pertenecientes a obras del mismo autor. Llevado a su extremo más radical, este procedimiento configura propuestas como la de Zampanó Teatro con su Calderón, ¿enamorado? del año 2000. La veterana compañía unió textos diversos del autor de La vida es sueño en una dramaturgia que pretendía ofrecer una panorámica de la producción calderoniana en el cuarto centenario del nacimiento del autor.

Un tercer nivel de trabajo con los textos áureos para la escena contemporánea lo constituye la fusión de varias piezas de autores coetáneos que tienen en común el estilo, la temática o el género dramático desarrollado. Un ejemplo en este sentido lo constituye La fiesta barroca, espectáculo de la CNTC compuesto por diferentes piezas breves de Calderón y Quiñones de Benavente en una dramaturgia a cargo de Rafael Pérez Sierra. Si las obras de índole religiosa vertebraron este montaje estrenado en 1992, los entremeses han hilvanado innumerables propuestas teatrales, como la de Teatro Corsario con Clásicos locos, en 1994. Fernando Urdiales, autor de la versión de los textos, dirigió un hilarante espectáculo que contenía El sombrero, de Francisco de Castro, El retrato vivo, de Agustín Moreto,

8. En todo caso, cuando el adaptador de un texto clásico basa su trabajo en el procedimiento del corte o la supresión, Brook aconseja con cautela que, "si se tiene un cuchillo en una mano, la otra necesita el estetoscopio” (2012: 115). Y ello para prevenir posibles incongruencias o alteraciones de sentido en la obra. 
Los sordos, entremés anónimo, Los poetas locos, de Sebastián de Villaviciosa, El reloj y figuras de la venta y Las visiones de la muerte, de Calderón de la Barca.

Pero los dramaturgos áureos también han compartido un mismo espectáculo con autores de épocas distintas gracias a dramaturgias misceláneas que han tenido como hilo conductor un determinado motivo o temática. Es el caso del espectáculo Regalo de dioses, estrenado en el Teatro Romea de Murcia en 1993 en coproducción con la Universidad de Murcia. César Oliva, director, escenógrafo, figurinista y también adaptador de los textos, utilizó fragmentos de Las Bacantes, de Eurípides, Las ranas, de Aristófanes, Anfitrión, de Plauto, Representación del Nacimiento, de Gómez Manrique, Auto de la prevaricación de nuestro padre Adán, de autoría anónima, La Celestina, de Fernando de Rojas y Mojiganga de las visiones de la muerte, de Calderón de la Barca.

Todos ellos son ejemplos de espectáculos que entrelazan textos de diversas procedencias. Pero los mecanismos del adaptador se suelen aplicar en el seno de un único texto barroco. Joan Oleza, en su labor de adaptación de La estrella de Sevilla (1998) para el montaje de Narros en la CNTC, puso en práctica un gran abanico de recursos e, incluso, incorporó versos creados por él mismo para una pieza de problemática atribución dentro del repertorio áureo. Oleza así lo justifica:

\begin{abstract}
En el caso de La estrella de Sevilla, debe tenerse en cuenta que se trataba de un texto que nos había llegado muy degradado. De hecho, para mí se trata de un texto refundido en el que han intervenido varias manos en distintos momentos. No obstante, al mismo tiempo, es un texto dramático magnífico. Todo ello me llevó a intervenir en él a fin de concederle la mayor calidad estética posible. Para ello hice uso de versos de otras comedias de Lope o adapté determinados pasajes muy deturpados siguiendo motivos e ideas presentes en otras obras del siglo XVII y de autores como Cervantes o Quevedo. Finalmente, sometí mis adaptaciones en verso al criterio de algunos amigos poetas y ellos me ayudaron a moldear los versos de mi cosecha para la adaptación. (2014)
\end{abstract}

A medida que el adaptador se aleja del original a través de la incorporación de materiales ajenos, la versión gana enteros en creación personal al tiempo que disminuye en fidelidad al texto primitivo. Es entonces cuando el director suele usar las etiquetas de versión libre de o inspirado en, o cuando -en el caso de ser obviadas- son reclamadas por los defensores del concepto de autoría como tributo de respeto al dramaturgo clásico. En este tipo de trabajos de adaptación resulta frecuente el cambio del título del original con el objetivo de advertir al 
espectador de que va a asistir a una lectura de director a partir de una obra clásica. El título de La vida es sueño es, posiblemente, el que mayores revisiones ha experimentado en este sentido: La vida es sueño 0.4, espectáculo estrenado en el Teatro Infanta Isabel de Madrid por la Asociación Cultural Conde de Aranda en 2003, Y los sueños, sueños son, una producción de Tropos estrenada el mismo año, o Sexismunda, del año 2001, por la compañía gallega Sarabela ${ }^{9}$.

Explica Oliva que la mecánica de la adaptación "nunca tuvo una normativa precisa ni homologada; no dispone de una auténtica gramática” (2009: 204). Para este especialista -uno de los estudiosos españoles que más ha reflexionado en torno a la adaptación de los textos barrocos-, imaginación, talento, estudio, sensatez y rigor constituirían las características del adaptador ideal, "un adaptador que puede elegir el modo de ajustar que desee, desde la pura revisión arqueológica hasta la actualización, siempre que impere la cordura y saber hacer” (2009: 205). En el siglo XXI, el problema de la adaptación de los clásicos ya no lo es. Las posturas radicales de ruptura y transgresión se han suavizado en aras al respeto a la esencia original definida por el dramaturgo. A su vez, las posiciones más intransigentes han comprendido que, si en pintura se acepta que, por ejemplo, el Equipo Crónica dé su propia visión de Las meninas de Velázquez sin que la obra original peligre, ¿por qué no es posible admitir el juego escénico de un director a partir de una comedia barroca? En realidad, los textos como tales están preservados por la filología. Y todas las adaptaciones, versiones y relecturas nunca serán capaces de borrar el original de Tirso, Lope o Calderón.

Así es como dos polémicas que han recorrido el siglo XX, la forma de decir el verso y la adaptación del texto original, dos cuestiones que han atravesado las diferentes etapas de la puesta en escena moderna y que han servido como arma arrojadiza para los defensores de posturas maximalistas, han visto florecer en torno a ellas unos amplios niveles de consenso. Las viejas y eternas disputas teatrales de capa y espada relativas al verso y la adaptación, que enrocaron más si cabe a los bandos del teatro y la filología durante décadas, se han visto sustituidas por una pax teatral que a todas luces redunda en beneficio del teatro clásico y de su recepción contemporánea.

9. El texto de La vida es sueño ha sido objeto de adaptaciones de toda índole a lo largo de los siglos. Véase, para las más recientes en España, el trabajo de Sergio Adillo (2014: 1-21). 


\section{Bibliografía}

ADILLO, S. (2014). "La adaptación de un texto clásico para su puesta en escena hoy. El caso de La vida es sueño" en Diálogos en las tablas. Últimas tendencias de la puesta en escena del teatro clásico español. (Eds. M. Bastianes, E. Fernández y P. Mascarell). Kassel: Reichenberger.

BINGHAM KIRBY, C. (1992). "Hacia una definición precisa del término refundición en el teatro clásico español” en Actas del X Congreso de la Asociación Internacional de Hispanistas. Barcelona, 21-26 de agosto de 1989. (coord. A. Vilanova). Barcelona: Promociones y Publicaciones Universitarias, 1992.

BROOK, P. (2012). El espacio vacío. Barcelona: Península.

DORT, B. (1988). La représentation émancipée. Arles: Actes Sud, 1988.

GRANDA MARTÍN, J. J. (2000). "Calderón, los cómicos y el verso en el siglo XX” en Calderón en escena: siglo XX. (eds. J. M. ${ }^{a}$ Díez Borque y A. Peláez). Madrid: Consejería de Cultural de la Comunidad de Madrid.

HIPÓLITO, C. (1999). "El actor de hoy frente al teatro del Siglo de Oro" Actas de las Jornadas XIV celebradas en Almería (marzo, 1997). (coords. A. de la Granja, H. Castellón y A. Serrano). Almería: Instituto de Estudios Almerienses.

HORMIGÓN, J. A. (ed.) (1983). El trabajo con los clásicos en el teatro contemporáneo. V Jornadas de Teatro Clásico Español, Almagro, 1982. Madrid: Dirección General de Música y Teatro del Ministerio de Cultura.

HUERTA CALVO, J. (2006). "Primera parte. Análisis”. Cuadernos de Teatro Clásico. Clásicos entre siglos 22: 25-160.

HUERTA CALVO, J. (2012). "La Compañía Nacional: la fiesta de los clásicos”. Cuadernos de Teatro Clásico. 25 años de la CNTC. Un viaje hacia el futuro 28 (I): 69-82.

MASCARELL, P. (2014). El Siglo de Oro en la escena contemporánea. La Compañia Nacional de Teatro Clásico (1986-2011). València: Universitat de València.

MASCARELL, P. (2014). “Calderón y Marsillach van al cine. Una lectura irónica y lúdica del de la comedia de capa y espada Antes que todo es mi dama desde la escena”. Hipogrifo. Revista de literatura y cultura del Siglo de Oro 2.1: 55-72.

MEDINA VICARIO, M. (1987). "Entrevista con Adolfo Marsillach”. Reseña 172: 34-37.

MUÑOZ CARABANTES, M. (1992). Puesta en escena y recepción del teatro clásico y medieval en España (desde 1939 a nuestros días). Madrid: Universidad Complutense de Madrid. 
NIEVA, F. (1983). "La adaptación de los clásicos, un falso problema” en El trabajo con los clásicos en el teatro contemporáneo. V Jornadas de Teatro Clásico Español, Almagro, 1982. (ed. J. A. Hormigón). Madrid: Dirección General de Música y Teatro del Ministerio de Cultura.

OLIVA, C. (2009). Versos y trazas. Murcia: Universidad de Murcia.

OLEZA, J. (ed.) (1998). La estrella de Sevilla, atribuida a Lope de Vega. Madrid: Compañía Nacional de Teatro Clásico.

OLEZA, J. (2014). "El auge escénico de la comedia ha desligado el teatro barroco del 'espíritu nacional' de Franco” en Diálogos en las tablas. Últimas tendencias de la puesta en escena del teatro clásico español. (eds. M. Bastianes, E. Fernández y P. Mascarell). Kassel: Reichenberger.

PELÁEZ, A. et al. (1996). "El actor y la actriz ante el teatro clásico (Mesa redonda)" en En torno al teatro del Siglo de Oro: actas de las XII-XIII Jornadas de Teatro del Siglo de Oro celebradas en Almería. (coord. J. J. Berbel Rodríguez). Almería: Instituto de Estudios Almerienses.

PÉREZ-RASILLA, E. (2008). "La puesta en escena de los clásicos. La crítica académica”. Acotaciones. Revista de investigación teatral 20: 9-22.

RODRÍGUEZ CUADROS, E. (2012). El libro vivo que es el teatro. Canon, actor y palabra en el Siglo de Oro. Madrid: Cátedra.

SANCHIS SINISTERRA, J. (2006). "Adaptar/adoptar” en 20 años en escena (1986-2006). Madrid: Compañía Nacional de Teatro Clásico.

SEGURA, F. (1986). “El castigo sin venganza. ¡Ay, el verso!”. Reseña 160: 5-7.

WHEELER, D. (2012). Golden Age Drama in Contemporary Spain. Cardiff: University of Walles Press. 